\title{
HIV positive secondary gastric syphilis with Helicobacter Pylori infection, a case report and literature review
}

\author{
Jingli Zhang ${ }^{1 *}$, Na Wei ${ }^{2}$, Weifeng $\mathrm{Li}^{1}$, Qun Huang ${ }^{1}$, Guo Hu${ }^{1}$ and Yizhi Tang ${ }^{3}$ \\ ${ }^{1}$ Department of Pathology, 363 Hospital, Chengdu, China \\ ${ }^{2}$ Department of Gastroenterology, 363 Hospital, Chengdu, China \\ ${ }^{3}$ Department of Ultrasound, 363 Hospital, Chengdu, China
}

\begin{abstract}
Gastric syphilis is an uncommon disease, presenting nonspecific clinical and histological features. We present a rare case of 17-year-old women who had 2-week abdominal pain and sought for medical help. The patient was diagnosed with gastric syphilis, concomitantly infected with Helicobacter pylori (HP) and human immunodeficiency virus (HIV). The coexistence of HP and Treponema pallidum (TP) in gastric tissue was proved by immunohistochemical (IHC) staining. Multiple infections made diagnosis difficult. Comprehensive analysis of clinical, endoscopic, serological, and histopathologic data can avoid missed diagnosis.
\end{abstract}

\section{Introduction}

Syphilis is a sex-transmitted disease caused by Treponema pallidum (TP), which has been described since the 15th century. Although the incidence of syphilis has been raising in China in recent years, gastric syphilis is still uncommon. In most cases, gastric syphilis can be hardly taken into consideration in dealing with gastritis diseases, makes it easy to misdiagnose gastric syphilis. We report here a human immunodeficiency virus (HIV) positive young patient who has been infected by TP and Helicobacter Pylori (HP) concomitantly, leading to gastritis and large gastric ulcer. It is extremely rare. The patient accepted a delayed treatment due to late diagnosis of gastric syphilis. It's a great challenge for both pathologist and physician $t$ recognize gastric syphilis through nonspecific clinical and histologic characters. The identification of TP in biopsy specimen provides the absolute evidence for gastric syphilis [1], immunohistochemical (IHC) staining for TP helps confirming gastric syphilis in our case.

\section{Case report}

A 17-year-old Tibetan woman complained of continuous abdominal pain for about 2 weeks, which worsen after meal or during the night. Gastroscopy inspection revealed extensive mucosal erosion, and a large irregular-shaped ulcer with bleeding on antrum, the ulcer size was about $3 \mathrm{~cm} \times 2 \mathrm{~cm}$, gastric mucosa thickened, with nodular aspect, the aspect of gastroscopy was similar to that of tumor (Figure1 A). Gastric histopathology revealed shallow erosion, chronic inflammation with dense lymphocytic and plasmacytic infiltration, neutrophil and histocyte were also observed in mucosa. There was no obvious vasculitis. Mucosal gland was destroyed and depleted in numbers, granulation tissue hyperplasia and lymphoid follicular formed focally. Only a few inflammatory cells infiltrate in muscularis mucosae. There was no specific histologic image (Figure 2A and Figure 2B).

Proton pump inhibitors (PPI) and gastric mucosal protect agent were administered. However, the symptoms did not relieve after 6-day treatment. Patient was admitted to hospital. 14C urea breath test was positive. Patient was given anti-HP agent, PPI and mucosal protection agent, but symptom persisted. Blood test revealed positive result for both TP (both RPR 1:128 and specific antibody) and HIV. Tumor markers including AFP, CEA, CA199, and CA125 were negative. HIV infection was confirmed later. Gynecologic examination observed some painless papulae in vulva. Papula was pale and tough, with ulcer (Figure 3A). The patient was sexually active and had history of oral sex. Vulva cutaneous biopsy showed squamous epithelial hyperplasia, with superficial erosion, where some neutrophils were observed. Plenty of mixed inflammatory cells, predominantly lymphocytes and plasmocytes infiltrated in a lichenoid pattern in corium layer and subcutaneous layer. Angiogenesis and vasculitis could be observed, plasmocytes around vessel formed perivasucular cuffing. Based on these results, we conducted IHC staining for HP, TP and markers of inflammatory cells.

\section{TP IHC staining}

Gastric biopsy tissue revealed lots of thread-like organisms scattered in the mucosa where dense inflammatory cells infiltrated. The pathogen could also be seen in exudation and mucus. Small amount treponema distributed in muscularis mucosae and mild inflammatory mucosa. The distribution area of TP is similar as that of inflammatory cell. The denser inflammatory cells infiltrate, the more TP could be seen (Figure 2C and 2D). In vulva cutaneous biopsy slice, TP IHC staining revealed epitheliotropic pattern, abundant organisms were observed in lower epidermis of erosion area, where treponema was located in intercellular space, which draw outline of squamous epithelial cell (Figure 2E).

${ }^{\star}$ Correspondence to: Jingli Zhang, Department of Pathology, 363 hospital, Chengdu, China, Tel: (+86) 18780056446; E-mail: zhjl363hospital@163.com

Key words: gastric syphilis, Helicobacter Pylori, human immunodeficiency virus, immunohistochemistry, differential diagnosis

Received: October 30, 2020; Accepted: November 13, 2020; Published: November 16, 2020 

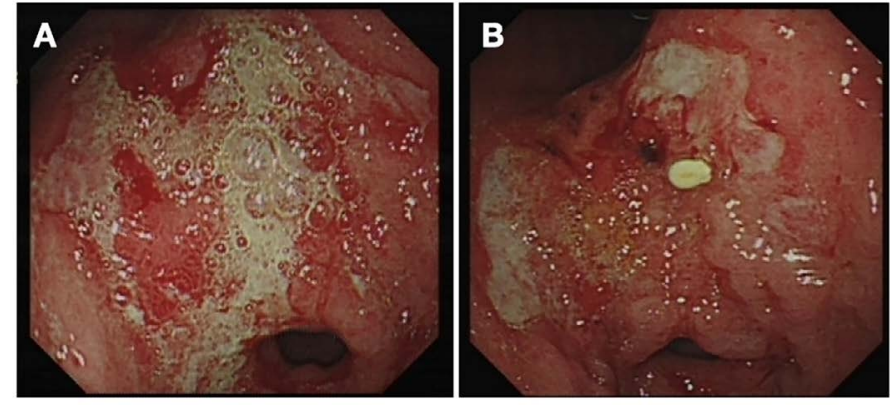

Figure 1. Upper endoscopic picture showing: (A) large exudative ulcer on antrum, before HP eradicative and anti-TP treatment and (B) the large ulcer become smaller after treatment.

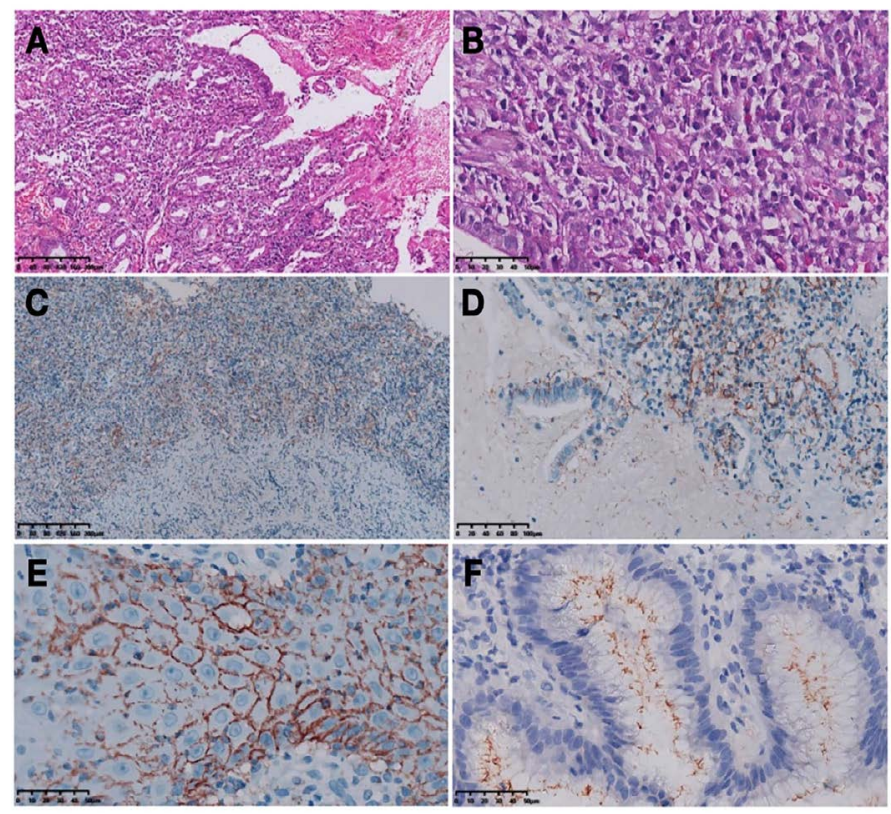

Figure 2. Gastric biopsy reveals (A) mucosa erosion, with severe inflammation (HE staining, X100), (B)mixed inflammatory cell infiltration, mailly lymphocytes and plasmocytes (HE staining, X400). Immunohistochemical staining for TP of the biopsied gastric lesions showing $(C)$ most of the pathogen distribute in epithelial and lamina propria, few of them in muscularis mucosa (IHC staining, X100), (D) plenty of TP in mucosa and mucus (IHC staining, X200). (E) In vulva lesion biopsy, TP immunohistochemical staining reveals pathogen distribution around squamous epithelial (IHC staining, X400). (F) HP immunohistochemical staining of the biopsied gastric lesions showing some pathogen on the superficial of mucosa (IHC staining, X400).

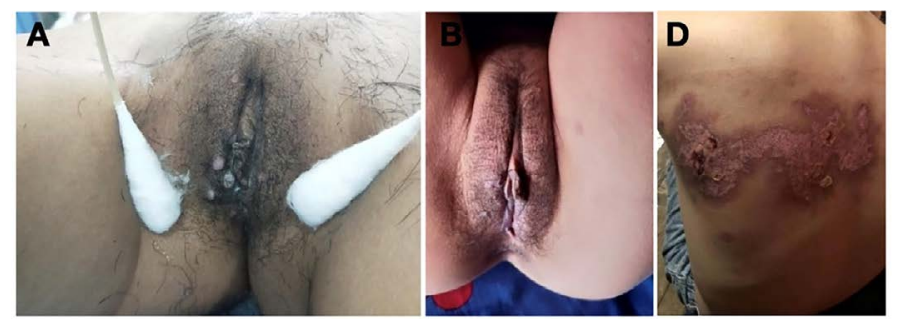

Figure 3. (A) Some pale, hard and painless papula in valva. (B) The papula disappeared after anti-TP treatment (c) Severe herpes zoster virus infection, which leads to ulceration on back.

\section{HP IHC staining}

The IHC staining slice of the gastric biopsy specimen revealed some rod-like or point-like HP organisms scattered on the superficial of mucosa (Figure 2F).

\section{Inflammatory cells IHC staining}

Lymphocyte and plasmocyte were most common in gastric mucosal specimen, with some neutrophil and histocyte infiltration. Number of lymphocytes was more than that of plasmocyte. Of the lymphocytes, most were CD20 positive cells and less CD3 positive cells.

Based on laboratory and pathologic findings, diagnosis of gastritis concomitant with HP, TP, and HIV infections was made. The patient was given additional anti-TP treatment. After 7-day treatment, gastric symptoms improved and vulva papula disappeared gradually (Figure 3B). The following gastric endoscopy observed the shrinked gastric ulcer (Figure 1B).

Biopsy histology still revealed non-specific chronic inflammation and IHC staining for TP remained positive, but declined in numbers. HP staining was negative. After the therapy, symptoms disappeared entirely. A blood test 8 -month later showed that TP specific antibody is positive. The patient refused gastroscopic check. Meanwhile, she suffered a serious herpes zoster virus infection with a large ulcer on her back (Figure 3C).

\section{Discussion}

Syphilis is not rare nowadays, but stomach was hardly involved. Based on the past study, only $1 \%$ of syphilis involved stomach [2]. Morton referred that the first 2 cases of gastric syphilis reported in 1836 by Andral [3]. Hereafter, more cases of gastric syphilis were reported gradually, some cases infected with HP concurrently [1,4-8], and other studies found gastric syphilis were HIV positive simultaneously $[9,10]$. However, gastric syphilis with both HP and HIV infection simultaneously have not been reported so far.

The reported median age of gastric syphilis was 39 years old, with range of 21-78 years [1]. Our case is 17-year-old women, younger than document record. About $63 \%$ gastric syphilis were in male, especially those who had sex with man [1]. All patient who has sex activities should not be ruled out the possibility of gastric syphilis. Epigastric/ abdominal pain was the most common symptom [1], which occurred in our case. Early satiety, weight loss, upper gastrointestinal bleeding was not uncommon [1,4]. Most of gastric syphilis had no prior syphilis diagnosed, but serology was nearly always positive [1]. TP positive of serologic test should be a strong evidence for syphilis. Findings from upper gastric endoscopy vary widely, including gastric ulcer, nodular mucosa, extensive erosion, large ulcer, thickened fold, narrowing and rigidity, mass lesion, etc. $[1,11]$. A systematic review found that endoscopic feature related to staging of gastric syphilis. In early stage, it tends to be diffused erosion, large irregular ulcer, mucosa thicken and mass-like lesion. In later period, chronic inflammation results in fibrotic rigidity and narrowing of the gastric wall. The earlier diagnosis of gastric syphilis, the better the outcome. Ulcerative gastritis was almost equally reported in both early and late stage [1]. The antrum was not only the most commonly involved area of gastric syphilis [1], but also the most frequently involved part of HP. Syphilis was known as "the great mimicker", endoscopic images of gastric syphilis often made endoscopic physicians confused for it could mimic lymphoma, carcinoma, Crohn disease and tuberculosis $[1,12,13]$. In our case, endoscopic physician initially suspected tumour. Some gastric syphilis cases present TP and HP simultaneously and whether HP played an assistant role in developing of gastric syphilis was doubted [1]. In our case, HP infection was found first, but HP eradication treatment was not effective. The subsequent anti-TP treatment relieved abdominal pain in a few days. 
Finding TP in gastric biopsy specimen provides a solid evidence of gastric syphilis. IHC staining is a simple and convenient way to confirm pathogen with high specificity and is more sensitive and specific than silver stain $[14,15]$. However, while gastric syphilis is admitted to differential diagnosis, given the fact that HP has been found in some gastric syphilis cases, ordering TP and HP IHC staining would be a wise choice. The histologic features of gastric syphilis are not specific for diagnosis. Our observation is consistent with previous reports that gastritis was infiltrated with dense mixed inflammatory cells, mainly composed of lymphocyte and plasmocyte $[1,4,16]$. According to IHC staining, most lymphocytes were B cells, and their amount was more than that of plasmocyte. Interestingly, the density of inflammatory cell seems serving as an indicator for the distribution of treponema. Vasculitis was not found in gastric biopsy specimen, but plasma cell vasculitis (perivasucular cuffing) was observed in vulva biopsy tissue. A group of diseases are histologically similar to gastric syphilis.

\section{HP infection}

Histologic feature of HP-associated gastritis is like that of gastric syphilis. Diagnosis of HP-associated gastritis is not the end. HP is often concomitant with TP, if patient were diagnosed with syphilis, or serologic positive for TP, gastric syphilis should be taken into differential diagnosis.

\section{Phlegmonous gastritis}

Phlegmonous gastritis often has similar gastroscopic image as gastric syphilis, such as thicken fold, ulcer, and mass effect. This two gastritis could also have similar histologic features. However, syphilis related inspection would be helpful.

\section{Autoimmune gastritis}

Autoimmune gastritis usually occurs in old female, antrum and angle are often involved. In the early stage of the disease, histologic changes might be confused with gastric syphilis. But differ from gastric syphilis, intestinal metaplasia and the enterochromaffin-like (ECL) cell hyperplasia can often be seen. Clinical data and TPIHC staining could help differential diagnosis [17]. Meanwhile, lymphoma and carcinoma should be ruled out.

\section{Conclusion}

Lacking specific clinical and pathological characteristics, seize the suggestive clues would prevent missed diagnosis from happening. Doctors should always be alerted the possibility of gastric syphilis in the following situations.

1. Patient who has epigastric/abdominal pain or other gastric symptoms.

2. Endoscopic inspection shows diffuse erosion, thicken mucosa or large ulcers on antrum.
3. Patient has been diagnosed with syphilis before or has possibility of syphilis, serology test would be helpful in this case.

4. Gastric mucosa infiltrate with dense lymphocytes and plasmocytes histopathologically.

5. Patient is HP infected, but HP eradicative treatment has no obvious effect. However, if gastric syphilis is suspected, TP IHC staining is helpful, and try to look for trepenema in severe inflammation area.

\section{Acknowledgments}

This study was supported by Technology Support Program of Sichuan Province, China (2019YFS0444).

\section{References}

1. Mylona EE, Baraboutis IG, Papastamopoulos V, Tsagalou EP, Vryonis E, et al. (2010) Gastric syphilis: a systematic review of published cases of the last 50 years. Sex Transm Dis 37: 177-83. [Crossref]

2. Chiari H (1891) Ueber Magensyphilis. Festschrift Virchow 2: 279-295.

3. Morton CB (1932) Syphilis of the stomach. Arch Surg 25: 880-889.

4. Greenstein DB, Wilcox CM, Schwartz DA (1994) Gastric syphilis: Report of seven cases and review of the literature. J Clin Gastroenterol 18: 4-9. [Crossref]

5. Rank EL, Goldenberg SA, Hasson J, Cartun RW, Grey AN (1992) Treponema pallidumand Helicobacter pylori recovered in a case of chronic active gastritis. $\mathrm{Am} \mathrm{J}$ Clin Pathol 97: 116-120. [Crossref]

6. Liu XL, Omar H (2010) Treponema pallidum immunostain distinguishing syphilitic gastritis from Helicobacter pylori-associated gastritis. Hum Pathol 41: 617-619. [Crossref]

7. Fyfe B, Poppiti RJ, Lubin J, Robinson MJ (1993) Gastric syphilis. Primary diagnosis by gastric biopsy: report of four cases. Arch Pathol Lab Med 117: 820-823. [Crossref]

8. Neafie RC, Marty AM (1993) Unusual infictions in humans. Clin Microbiol Rev 6 : 34-56. [Crossref]

9. Kasmin F, Reddy S, Mathur-Wagh U, Sarlin J, Goldman A, et al. (1992) Syphilitic gastritis in an HIV-infected individual. Am J Gastroenterol 87: 1820-1822. [Crossref]

10. Guerrero AF, Straight TM, Eastone J, Spooner K (2005) Gastric syphilis in an HIVinfected patient. AIDS Patient Care STDS 19: 281-285. [Crossref]

11. Souza Varella Frazão M, Guimarães Vilaça T, Olavo Aragão Andrade Carneiro F, Toma $\mathrm{K}$, Eliane Reina-Forster C, et al. (2012) Endoscopic aspects of gastric syphilis. Case Rep Med 2012: 646525. [Crossref]

12. Long BW, Johnston JH, Wetzel W, Flowers RH 3rd, Haick A (1995) Gastric syphilis Endoscopic and histological features mimicking lymphoma. $A \mathrm{~m}$ J Gastroenterol 90: 1504-1507. [Crossref]

13. Okamoto K, Hatakeyama S, Umezawa M, Hayashi S (2018) Gastric syphilis: The great imitator in the stomach. ID Cases 12: 97-98. [Crossref]

14. Hoang MP, High WA, Molberg KH (2004) Secondary syphilis: a histologic and immunohistochemical evaluation. J Cutan Pathol 31: 595-599. [Crossref]

15. Liu XL, Hameed Omar (2010) Treponema pallidum immunostain distinguishing syphilitic gastritis from Helicobacter pylori-associated gastritis. Hum Pathol 41: 617619. [Crossref]

16. Osman M, Hasan S, Azher Q, Elbedawi M, Bachuwa G (2018) Syphilitic gastritis: a rare presentation of secondary syphilis. BMJ Case Rep 2018: bcr2017223868. [Crossref]

17. Montgomery EA, Voltaggio L (2012) Biopsy interpretation of the gastrointestinal tract mucosa. (2n edn), Wolters Kluwer Health Adis (ESP).

Copyright: (C2020 Zhang J. This is an open-access article distributed under the terms of the Creative Commons Attribution License, which permits unrestricted use, distribution, and reproduction in any medium, provided the original author and source are credited. 